\title{
Analysis on the Motivation and Countermeasures of Financial Fraud in ZX Company -- Based on Fraud Risk Factor Theory
}

\author{
Shouyong $\mathrm{Li}^{1, *}$ \\ ${ }^{1}$ Enter Author Affiliation 1 (Business School of Guilin University of Technology, Guilin, 541004, China) \\ *Corresponding author. Email: 785776016@qq.com
}

\begin{abstract}
The advent of the era of big data has promoted the rapid development of China's telecommunications enterprises. However, recently, ZX Company was given administrative punishment by China Securities Regulatory Commission for financial fraud for seven consecutive years. This fraud scandal not only brought serious losses to the majority of investors who are optimistic about the development of the telecom industry, but also caused extremely bad social impact. Based on the fraud risk factor theory, this paper firstly reviews the financial fraud event of ZX Company, then analyzes the causes of the fraud from the standpoint of ZX Company, and finally puts forward targeted prevention suggestions for the financial fraud of telecommunications enterprises.
\end{abstract}

Keywords: Financial fraud, Fraud risk factor theory, Telecom enterprise.

\section{INTRODUCTION}

\subsection{Basic information of ZX Company}

ZX Information Industry Co., Ltd. was established in 1997 and listed on Shenzhen Stock Exchange in October of the same year. It is mainly engaged in the investment and construction of cable television network and satellite communication network, as well as the development and production of new materials.
With the vigorous development of the telecommunications industry in recent years, ZX Company has achieved considerable business performance. As shown in Figure 1, the gross profit and net profit of ZX Company have been increasing year by year from 2016 to 2018. In 2019, because of the transfer of the equity of its subsidiaries, ZX Company will no longer include them in the scope of consolidated statements. ZX Company's revenue, gross profit and net profit all decreased in the year. 


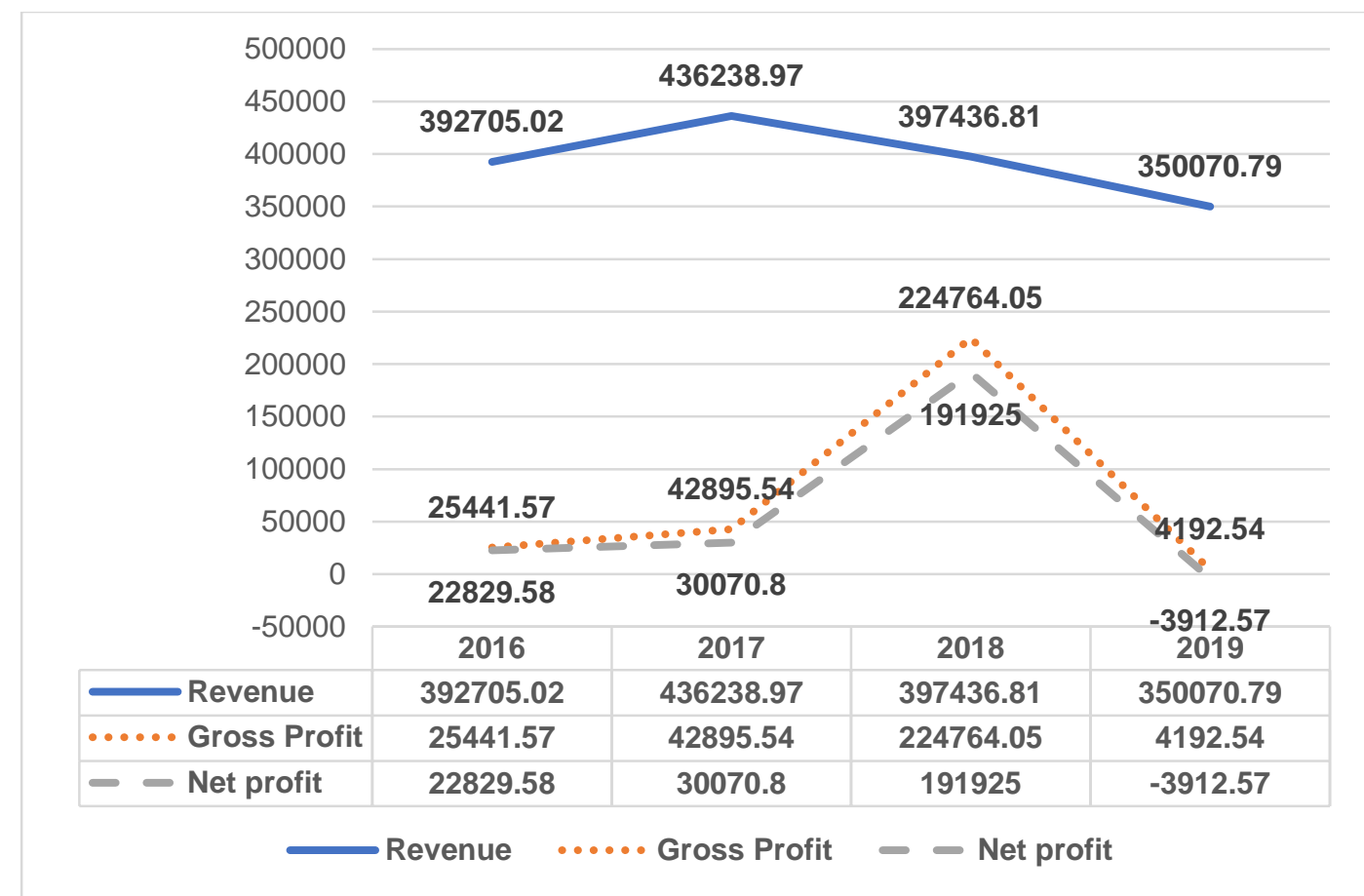

Figure 1 Operating Revenue, Operating Profit and Net Profit of ZX Company from 2016 to 2019 (Unit: ten thousand Yuan)

\subsection{ZX Company Financial Fraud Event}

In April 2009, in order to attract investors to buy the company's shares, ZX's senior executives held a special sales meeting and set the annual revenue target of 1 billion yuan. However, according to the actual capacity of the company, it is expected that the maximum operating income can only reach 400 million yuan. In order to achieve the established performance target, ZX Company decided to sign contracts with 10 customer companies in the way of pre-sale, with the profit at $10 \%$ price, and pay customers the interest of advance payment according to the commercial loan rate of the same period. After receiving the pre-sale payment from customers, ZX Company falsified the sales contract of goods, delivery bill and other materials to increase revenue and form accounts receivable. At the end of the month, the advance receivable and accounts receivable are offset and verified. From 2009 to 2015, ZX Company falsely increased its operating revenue by RMB 506 million, undercounted financial expenses by RMB 507 million, and increased its profit by RMB 1.012 billion.

In March 2021, China Securities Regulatory Commission issued a penalty announcement on ZX Company, planning to order it to correct, give it a warning, and impose a fine of RMB 600,000; Nine people responsible were given warnings and fined between 50,000 yuan and 300,000 yuan. After the fraud incident was exposed, ZX's share price fell sharply by the daily limit, and 190,000 shareholders suffered heavy losses.

\section{THEORY OF FRAUD RISK FACTORS}

According to Niu Yiheng ${ }^{[1]}$ (2020) and Ma Liangyu [2] (2020), the fraud risk factor theory consists of individual risk factors and general risk factors.

Individual risk factors include motivation to commit fraud and moral character. Motivation of fraud is the power and idea that guide individuals to engage in financial fraud. Moral character refers to the concept standard of the individual to measure the propriety of behavior. General risk factors include the opportunity for fraud, the severity of penalties, and the probability of exposure. The chance of fraud often stems from the significant design defect or operation failure of the company's internal control; The punishment for fraud by the supervision department determines the cost of the fraud. Exposure probability refers to the possibility that fraud is discovered by the internal and external regulatory mechanisms of the company.

Fraud is very likely to occur if individuals seek improper interests and derive fraud motivation, and their moral character cannot properly restrain their own behavior. At the same time, the internal control mechanism of the company is not perfect, and the punishment of the regulatory department is light, so the exposure probability of fraud will be reduced, and the possibility of being discovered will be smaller. 


\section{MOTIVATION ANALYSIS OF FINANCIAL FRAUD IN ZX COMPANY}

\subsection{Individual risk factors}

\subsubsection{Too much pressure on performance targets}

The ZX company financial fraud motivation is largely due to company executives unrealistic targets decisions blind confidence, the potential risk of serious neglect decision-making, and lead to the company to create sales goal gap is too big, therefore, the company's management and employees have to bear the excessive pressure from performance targets. In order to timely fulfill the performance commitment, stabilize the investor confidence and the company's stock price, ZX company can only take the risk to increase the revenue and profit in a fraudulent way and create a false appearance of a good development situation of the company.

\subsubsection{Management personnel lack of professional ethics}

In 2011, Luo, one of the people responsible for the fraud and the then director of ZX Company, said: "Don't compare money with ZX Company!" From this perspective, Luo assumed the responsibility of supervision and management of the company, but abandoned the professional ethics that a manager should have, and failed to observe the company's real financial situation diligently and responsibly. In addition, ZX company deputy general manager Li and others, but also due to the lack of professional ethics, the interests of investors and the long-term interests of the company far behind, personally planned this fraud.

\subsection{General risk factors}

\subsubsection{The company's internal controls are virtually nonexistent}

According to the internal control situation disclosed in the annual report of ZX Company, the company has established an internal control organizational structure composed of the general meeting of shareholders, the board of directors, the board of supervisors, the management and the holding subsidiaries and functional departments, and the board of supervisors should not only supervise the implementation effect of the internal control of the company. It also monitors the behavior of directors, general managers and other senior executives, as well as the financial status of the holding subsidiaries. The nine persons who were punished in this fraud event all held important positions in the company's management. The Board of Supervisors did not effectively supervise the behavior of senior executives and the company's financial situation due to the interests involved. The company's organizational structure was derelict at various levels and the internal control mechanism was virtually non-existent, which created good conditions for fraud. In addition, according to the articles of association of the company, the remuneration of directors, supervisors and senior managers of the company is deeply linked to the benefits of the company. In order to obtain more personal remuneration, the relevant responsible person is likely to whitewash the financial situation of the company through fraud.

\subsubsection{Punishment for violations is weak}

During the fraud year, ZX Company is subject to the Securities Law promulgated and implemented in 2005, which only imposes a maximum fine of 600,000 yuan for the illegal information disclosure of listed companies. According to the penalty announcement issued by the CSRC, the total fine is 1.85 million yuan, together with the company and nine relevant responsible persons. Compared with the high profits brought by financial fraud to ZX Company and the relevant responsible persons, the illegal cost is relatively low, which further encourages the arrogance of the fraudsters.

\subsubsection{Weaker supervision reduces the probability of fraud exposure}

From the point of view of the internal supervision, the company is equipped with independent audit department is responsible for internal audit work, the board also has the audit committee to supervise, but as a result of the operation of the company's internal control failure, the internal audit department for the company's internal audit work and audit committee often become a mere formality, even under pressure to complete those responsible fraud, led to the weakening the effectiveness of the internal supervision mechanism, In turn, the possibility of corporate financial fraud being discovered is greatly reduced.

\section{FINANCIAL FRAUD PREVENTION SUGGESTIONS OF TELECOMMUNICATION ENTERPRISES}

\subsection{Improve the enterprise risk assessment system, improve the scientific decision-making}

The primary reason for the financial fraud of ZX Company is that the company's senior executives only consider the immediate interests without considering the actual situation of the company and make wrong decisions. They also fail to fully evaluate the potential risks of the decision and raise due doubts, which eventually lead to the company's fraud due to excessive pressure. At present, China's telecom industry in the new age of industrial upgrading, many similar ZX company's telecommunications companies are trying to expand their 
scale, if the company in the absence of strong expansion decision risk assessment system as a support, not to reasonable control of operating risk, so decisions most likely lack of scientific, thereby deepening the company economic pressure. Therefore, telecom enterprises should constantly improve the construction of internal risk assessment system, make full discussions when making strategic decisions, and always take the longterm interests of the company as the starting point.

\subsection{Strengthen management personnel business ethics and professional ethics education}

The telecommunications industry is a sunrise industry with great potential for future development, which is bound to attract the attention of investors. Therefore, it is necessary to strengthen the business ethics education for the management personnel of telecommunications enterprises, so that they can fully understand the importance of respecting and protecting the rights and interests of investors, and improve their awareness of honest management. At the same time, it is also necessary to strengthen personal professional ethics education. Whether the management personnel or grass-roots workers, they should constrain their own behavior with correct professional ethics, strictly adhere to the moral bottom line, have a correct understanding of financial fraud and resolutely resist it, and curb fraud from the ideological perspective.

\subsection{Improve the company internal control system and reward and punishment assessment system}

Telecom enterprises should constantly improve the internal control system of the company. For companies with large business scale and complex business links, it is necessary to clearly implement the responsibilities of all departments and managers in all links of the company, and separate incompatible duties so that all businesses and funds can be carried out under effective control and supervision. For various accounting records, especially electronic records, special personnel should be entrusted to fill in, keep and review regularly in a unified format to ensure that the records are consistent with the actual situation. At the same time, the reward and punishment assessment system of the company should be constantly improved. In addition to taking post responsibilities and corporate benefits as the evaluation factors of the compensation of the company's senior executives, the assessment of the personal quality and professional quality of the senior executives should be paid attention to. The staff who conscientiously perform their duties should be appropriately rewarded and their enthusiasm should be fully aroused to play an exemplary role. Those who neglect their duties should be severely punished and a corporate atmosphere of strict reward and punishment should be established within the company.

\subsection{Intensify regulation and punishment of industries}

At present, the implementation of the new "Securities Law" has raised the upper limit of punishment for illegal behaviors of listed companies' information disclosure to 10 million yuan. The high cost of violation will undoubtedly have a certain deterrent effect on listed companies with financial fraud ideas. So regulators should continue to follow up regulation of the telecommunications industry, improve the relevant legal system construction, to fill the loopholes of the industry, the supervision of financial fraud company and the relevant responsible persons should impose heavy fines not only, still can according to its violation is sentenced to criminal punishment accordingly, alert other companies within the industry to eliminate financial fraud.

\subsection{Accelerate the process of enterprise information construction}

Telecommunication industry should make full use of its own information technology advantages, and constantly accelerate the process of enterprise information construction. On the one hand, it is necessary to promote the in-depth communication and collaboration between financial personnel and technical personnel, strengthen the training of intelligent technology for financial personnel, and promote the application of internal financial sharing mode. On the other hand, according to Mao Xin ${ }^{[3]}$ (2019), the internal audit department should make full use of big data technology set up internal audit system, based on data collected by the audit key issues and risk warning, and carrying out internal audit work, regulators also want to strengthen the audit information system for docking with telecom enterprise, using data technology to minimize the fraud exposure probability of telecom enterprises, prevent the occurrence of financial fraud.

\section{CONCLUSION}

The fight against financial fraud and prevention, always only in progress, not completed. With the help of the era of big data, all walks of life will be injected into the new development vitality, the regulatory authorities should play a good role of "referee", the supervision and punishment of financial fraud can not have the slightest slacking, to escort the rapid development of China's economy.

\section{REFERENCES}

[1] Niu Yiheng. Research on the Motivation and Governance of Financial Fraud of Listed Companies -- Based on the Common Perspective of Fraud Risk Factor Theory and Game Theory [J]. Journal of 
Finance and Accounting,2020(12):99-103.

[2] Ma Liangyu. Research on Motivation and Prevention Countermeasures of Corporate Financial Fraud Based on Risk Factor Theory -- Taking Jiuhao Group as an Example [J]. Fortune,2020(10):80-81.

[3] Mao Xin. Exploration and Research of Innovative Big Data Internal Audit in Telecom Industry $[\mathrm{J}]$. China Internal Audit,2019(01):28-33.
[4] Wei Lin, Xu Liwen, Liu Jia. An Empirical Study on Fraud in Financial Reporting of Listed Companies [J]. Audit Research,2011(02):98-106.

[5] Pan Kejing, Zhang Xuyao, Xu Dayu. A case study of financial fraud in ginseng and ginseng industry based on risk factor theory[J]. Business Accounting,2017(15):72-74. 